\title{
On Strong Convergence of Halpern's Method Using Averaged Type Mappings
}

\author{
F. Cianciaruso, G. Marino, A. Rugiano, and B. Scardamaglia \\ Dipartimento di Matematica ed Informatica, Universitá della Calabria, 87036 Arcavacata di Rende, Italy \\ Correspondence should be addressed to B. Scardamaglia; scardamaglia@mat.unical.it
}

Received 14 May 2014; Accepted 17 June 2014; Published 3 July 2014

Academic Editor: Luigi Muglia

Copyright (C) 2014 F. Cianciaruso et al. This is an open access article distributed under the Creative Commons Attribution License, which permits unrestricted use, distribution, and reproduction in any medium, provided the original work is properly cited.

Under suitable hypotheses on control coefficients, we study Halpern's method to approximate strongly common fixed points of a nonexpansive mapping and of a nonspreading mapping or a fixed point of one of them. A crucial tool in our results is the regularization with the averaged type mappings.

\section{Introduction}

Let $H$ be a real Hilbert space with the inner product $\langle\cdot, \cdot\rangle$, which induces the norm $\|\cdot\|$.

Let $C$ be a nonempty, closed, and convex subset of $H$. Let $T$ be a nonlinear mapping of $C$ into itself; we denote by $\operatorname{Fix}(T)$ the set of fixed points of $T$, that is, $\operatorname{Fix}(T)=\{z \in C: T z=z\}$.

We recall that a mapping $T$ is said to be nonexpansive if

$$
\|T x-T y\| \leq\|x-y\|, \quad \forall x, y \in C .
$$

The problem of finding fixed points of nonexpansive mappings has been widely investigated by many authors.

Halpern [1] was the first to consider the following explicit method:

$$
x_{1} \in C, \quad x_{n+1}=\alpha_{n} u+\left(1-\alpha_{n}\right) T x_{n}, \quad \forall n \geq 1,
$$

where $\left(\alpha_{n}\right)_{n \in \mathbb{N}} \subset[0,1]$ and $u \in C$ is fixed.

Moreover, Halpern proved in [1] the following theorem on the convergence of (2) for a particular choice of $\left(\alpha_{n}\right)_{n \in \mathbb{N}}$.

Theorem 1. Let $C$ be a bounded, closed, and convex subset of Hilbert space $H$ and let $T: C \rightarrow C$ be a nonexpansive mapping. For any initialization $x_{1} \in C$ and anchor $u \in C$, define a sequence $\left(x_{n}\right)_{n \in \mathbb{N}}$ in $C$ by

$$
x_{n+1}=n^{-\theta} u+\left(1-n^{-\theta}\right) T x_{n}, \quad \forall n \geq 1,
$$

where $\theta \in(0,1)$. Then $\left(x_{n}\right)_{n \in \mathbb{N}}$ converges strongly to the element of $\operatorname{Fix}(T)$ nearest to $u$.
He also showed that the control conditions,

$$
\begin{aligned}
& \text { (C1) } \lim _{n \rightarrow \infty} \alpha_{n}=0, \\
& \text { (C2) } \sum_{n=1}^{\infty} \alpha_{n}=\infty,
\end{aligned}
$$

are necessary for the convergence of (2) to a fixed point of $T$.

Subsequently, several authors carefully studied the following problem: are the control conditions $(\mathrm{C} 1)$ and $(\mathrm{C} 2)$ sufficient for the convergence of (2)?

In this direction, C. E. Chidume and C. O. Chidume [2] and Suzuki [3], independently, proved that the conditions $(C 1)$ and $(C 2)$ are sufficient to assure the strong convergence to a fixed point of $T$ of the following iterative sequence:

$$
\begin{gathered}
x_{1}, u \in C \\
x_{n+1}=\alpha_{n} u+\left(1-\alpha_{n}\right)\left(\lambda x_{n}+(1-\lambda) T x_{n}\right), \quad \forall n \geq 1 .
\end{gathered}
$$

Recently, in the setting of Banach spaces, Song and Chai [4], under the same conditions $(\mathrm{C} 1)$ and $(\mathrm{C} 2)$ but under stronger hypotheses on the mapping, obtained strong convergence of Halpern iterations (2). In particular, they assumed that $E$ is a real reflexive Banach space with a uniformly Gateâux differentiable norm and with the fixed point property for nonexpansive self-mappings, and considered an important subclass of nonexpansive mappings which is the firmly type nonexpansive mappings. 
Let $T$ be a mapping with domain $D(T) . T$ is said to be firmly type nonexpansive [4] if for all $x, y \in D(T)$, there exists $k \in(0,+\infty)$ such that

$$
\|T x-T y\|^{2} \leq\|x-y\|^{2}-k\|(x-T x)-(y-T y)\|^{2} .
$$

A more general class of firmly type nonexpansive mappings is the class of the strongly nonexpansive mappings. Recall that a mapping $T: C \rightarrow C$ is said to be strongly nonexpansive if

(1) $T$ is nonexpansive;

(2) $x_{n}-y_{n}-\left(T x_{n}-T y_{n}\right) \rightarrow 0$, whenever $\left(x_{n}\right)_{n \in \mathbb{N}}$ and $\left(y_{n}\right)_{n \in \mathbb{N}}$ are sequences in $C$ such that $\left(x_{n}-y_{n}\right)_{n \in \mathbb{N}}$ is bounded and $\left\|x_{n}-y_{n}\right\|-\left\|T x_{n}-T y_{n}\right\| \rightarrow 0$.

Saejung [5] proved the strong convergence of Halpern's iterations (2) for strongly nonexpansive mappings in a Banach space $E$ such that one of the following conditions is satisfied:

(i) $E$ is uniformly smooth;

(ii) $E$ is reflexive, strictly convex with a uniformly Gateâux differentiable norm.

In the setting of Hilbert spaces, Kohsaka and Takahashi [6] defined $T: C \rightarrow C$ a nonspreading mapping if

$$
2\|T x-T y\|^{2} \leq\|T x-y\|^{2}+\|x-T y\|^{2}, \quad \forall x, y \in C .
$$

The following Lemma is a useful characterization of nonspreading mapping.

Lemma 2 (see [7]). Let $C$ be a nonempty closed subset of Hilbert space $H$. Then, a mapping $T: C \rightarrow C$ is nonspreading if and only if

$$
\|T x-T y\|^{2} \leq\|x-y\|^{2}+2\langle x-T x, y-T y\rangle, \quad \forall x, y \in C .
$$

Observe that if $T$ is a nonspreading mapping from $C$ into itself and $\operatorname{Fix}(T) \neq \emptyset$, then $T$ is quasi-nonexpansive; that is,

$$
\|T x-p\| \leq\|x-p\|, \quad \forall x \in C, \forall p \in \operatorname{Fix}(T) .
$$

Further, the set of fixed points of a quasi-nonexpansive mapping is closed and convex [8].

Osilike and Isiogugu [9] studied Halpern's type for $k$ strictly pseudononspreading mappings $T$, which are a more general class of the nonspreading mappings.

To obtain the strong convergence of (2), they replaced the mapping $T$ with the averaged type mapping $T_{\delta}$, that is, with the mapping

$$
T_{\delta}=(1-\delta) I+\delta T, \quad \delta \in(0,1) .
$$

Iemoto and Takahashi [7] approximated common fixed points of a nonexpansive mapping $T$ and of a nonspreading mapping $S$ in a Hilbert space using Moudafi's iterative scheme [10]. They obtained the following Theorem that states the weak convergence of their iterative method.
Theorem 3. Let $H$ be a Hilbert space and let $C$ be a nonempty, closed, and convex subset of $H$. Assume that $\operatorname{Fix}(S) \cap \operatorname{Fix}(T) \neq \emptyset$. Define a sequence $\left(x_{n}\right)_{n \in \mathbb{N}}$ as follows:

$$
\begin{gathered}
x_{1} \in C \\
x_{n+1}=\left(1-\alpha_{n}\right) x_{n}+\alpha_{n}\left[\beta_{n} S x_{n}+\left(1-\beta_{n}\right) T x_{n}\right],
\end{gathered}
$$

for all $n \in \mathbb{N}$, where $\left(\alpha_{n}\right)_{n \in \mathbb{N}},\left(\beta_{n}\right)_{n \in \mathbb{N}} \subset[0,1]$. Then, the following hold.

(i) If $\lim \inf _{n \rightarrow \infty} \alpha_{n}\left(1-\alpha_{n}\right)>0$ and $\sum_{n=1}^{\infty}\left(1-\beta_{n}\right)<\infty$, then $\left(x_{n}\right)_{n \in \mathbb{N}}$ converges weakly to $p \in \operatorname{Fix}(S)$.

(ii) If $\sum_{n=1}^{\infty} \alpha_{n}\left(1-\alpha_{n}\right)=\infty$ and $\sum_{n=1}^{\infty} \beta_{n}<\infty$, then $\left(x_{n}\right)_{n \in \mathbb{N}}$ converges weakly to $p \in \operatorname{Fix}(T)$.

(iii) If $\lim \inf _{n \rightarrow \infty} \alpha_{n}\left(1-\alpha_{n}\right)>0$ and $\lim _{\inf _{n \rightarrow \infty}} \beta_{n}(1-$ $\left.\beta_{n}\right)>0$, then $\left(x_{n}\right)_{n \in \mathbb{N}}$ converges weakly to $p \in \operatorname{Fix}(S) \cap$ $\operatorname{Fix}(T)$.

In this paper, inspired by Iemoto and Takahashi [7], we introduce an iterative method of Halpern's type involving the averaged type mappings $T_{\delta}$ and $S_{\delta}$, where $T$ is a nonexpansive mapping and $S$ is a nonspreading mapping. The averaged type mappings $T_{\delta}$ and $S_{\delta}$ have a regularizing role in order to prove the strong convergence of our iterative scheme. In particular, we prove that the method strongly converges to the unique solution $z$ of the variational inequality

$$
\langle u-z, y-z\rangle \leq 0, \quad \forall y \in D,
$$

where $u \in C$ is an anchor and, depending on the hypotheses on control coefficients, $D$ is the set of fixed points of $T$, the set of fixed points of $S$, or the set of common fixed points of $T$ and $S$.

Suitable tools in our proofs are Maingé's Lemma [11] and some techniques used by Maingé in [12] to study the strong convergence of the viscosity approximation method. However, Wongchan and Saejung [13] found a small mistake in Maingés proof.

\section{Preliminaries}

To begin, we collected some lemmas which we will use in our proofs in the next section.

In the sequel, we denote by $H$ a real Hilbert space and by $C$ a nonempty closed convex subset of $H$.

Lemma 4. The following known results hold:

(1) $\|t x+(1-t) y\|^{2}=t\|x\|^{2}+(1-t)\|y\|^{2}-t(1-t)\|x-y\|^{2}$, for all $x, y \in H$ and for all $t \in[0,1]$,

(2) $\|x+y\|^{2} \leq\|x\|^{2}+2\langle y, x+y\rangle$, for all $x, y \in H$.

We recall that for every point $x \in H$, there exists a unique nearest point in $C$, denoted by $P_{C} x$, such that

$$
\left\|x-P_{C} x\right\| \leq\|x-y\|, \quad \forall y \in C .
$$

Such $P_{C}$ is called the metric projection of $H$ onto $C$.

Lemma [14] characterizes the projection $P_{C}$. 
Lemma 5. Let $C$ be a closed and convex subset of a real Hilbert space and let $P_{C}$ be the metric projection from $H$ onto $C$. Given that $x \in H$ and $z \in C$, then $z=P_{C} x$ if and only if there holds the inequality

$$
\langle x-z, y-z\rangle \leq 0, \quad \forall y \in C .
$$

By Lemma 5 , if $u \in C$ is fixed, $z=P_{C} u$ is the unique solution of the variational inequality (13).

To prove our main theorem, we need some fundamental properties of the involved mappings in the variational inequality.

The following result summarizes some significant properties of $I-T$ if $T$ is a nonexpansive mapping $([15,16])$.

Lemma 6. Let $C$ be a nonempty closed convex subset of $H$ and let $T: C \rightarrow C$ be nonexpansive. Then,

(1) $I-T: C \rightarrow H$ is (1/2)-inverse strongly monotone, that is,

$$
\frac{1}{2}\|(I-T) x-(I-T) y\|^{2} \leq\langle x-y,(I-T) x-(I-T) y\rangle,
$$

for all $x, y \in C$;

(2) moreover, if $\operatorname{Fix}(T) \neq \emptyset, I-T$ is demiclosed at 0 ; that is, for every sequence $\left(x_{n}\right)_{n \in \mathbb{N}}$ weakly convergent to $p$ such that $x_{n}-T x_{n} \rightarrow 0$ as $n \rightarrow \infty$, it follows $p \in \operatorname{Fix}(T)$.

Iemoto and Takahashi showed the demiclosedness of $I-$ $S$ at 0 and a suitable property of $I-S$. These results are summarized in the following two Lemmas.

Lemma 7 (see [7]). Let $C$ be a nonempty, closed, and convex subset of $H$. Let $S: C \rightarrow C$ be a nonspreading mapping such that $\operatorname{Fix}(S) \neq \emptyset$. Then, $I-S$ is demiclosed at 0 .

Lemma 8 (see [7]). Let $C$ be a nonempty, closed, and convex subset of $H$. Let $S: C \rightarrow C$ be a nonspreading mapping. Then,

$$
\begin{aligned}
\|(I-S) & x-(I-S) y \|^{2} \\
\leq & \langle x-y,(I-S) x-(I-S) y\rangle \\
& +\frac{1}{2}\left(\|x-S x\|^{2}+\|y-S y\|^{2}\right),
\end{aligned}
$$

for all $x, y \in C$.

If $T$ is a nonexpansive mapping of $C$ into itself, Byrne [15] defined the averaged mapping as follows:

$$
T_{\delta}=(1-\delta) I+\delta T=I-\delta(I-T),
$$

where $\delta \in(0,1)$.

Moreover, Byrne [15] and successively Moudafi [17] proved some properties of the averaged mappings; in particular, they showed that $T_{\delta}$ is a nonexpansive mapping. In this paper, inspired by $[15,17]$, we define the averaged type mapping $V_{\delta}$ as in (16) for a nonlinear mapping $V: C \rightarrow C$; we notice that $\operatorname{Fix}(V)=\operatorname{Fix}\left(V_{\delta}\right)$. It is easy to verify that if $S$ is a nonspreading mapping of $C$ into itself and $\operatorname{Fix}(S) \neq \emptyset$, the averaged type mapping $S_{\delta}$ is quasi-nonexpansive and consequently the set of fixed points of $S_{\delta}$ is closed and convex.

Actually, it follows from [9] that $S_{\delta}$ is quasi-firmly type nonexpansive mapping; that is, it is a firmly type nonexpansive mapping (5) on fixed points of $S$. For completeness we include the easy proof.

Proposition 9. Let $C$ be a nonempty closed and convex subset of $H$ and let $S: C \rightarrow C$ be a nonspreading mapping such that $\operatorname{Fix}(S)$ is nonempty. Then the averaged type mapping

$$
S_{\delta}=(1-\delta) I+\delta S
$$

is quasi-firmly type nonexpansive mapping with coefficient $k=$ $(1-\delta) \in(0,1)$.

Proof. We obtain

$$
\begin{aligned}
& \left\|S_{\delta} x-S_{\delta} y\right\|^{2} \\
& \quad=\|(1-\delta)(x-y)+\delta(S x-S y)\|^{2}
\end{aligned}
$$

(by Lemma 4)

$$
\begin{aligned}
= & (1-\delta)\|x-y\|^{2}+\delta\|S x-S y\|^{2} \\
& -\delta(1-\delta)\|(x-S x)-(y-S y)\|^{2}
\end{aligned}
$$

(by (7))

$$
\begin{aligned}
\leq & (1-\delta)\|x-y\|^{2} \\
& +\delta\left[\|x-y\|^{2}+2\langle x-S x, y-S y\rangle\right] \\
& -\delta(1-\delta)\|(x-S x)-(y-S y)\|^{2} \\
= & \|x-y\|^{2}+\frac{2}{\delta}\langle\delta(x-S x), \delta(y-S y)\rangle \\
& -\frac{1-\delta}{\delta}\|\delta(x-S x)-\delta(y-S y)\|^{2}
\end{aligned}
$$

(by (17))

$$
\begin{aligned}
= & \|x-y\|^{2}+\frac{2}{\delta}\left\langle x-S_{\delta} x, y-S_{\delta} y\right\rangle \\
& -\frac{1-\delta}{\delta}\left\|\left(x-S_{\delta} x\right)-\left(y-S_{\delta} y\right)\right\|^{2} \\
\leq & \|x-y\|^{2}+\frac{2}{\delta}\left\langle x-S_{\delta} x, y-S_{\delta} y\right\rangle \\
& -(1-\delta)\left\|\left(x-S_{\delta} x\right)-\left(y-S_{\delta} y\right)\right\|^{2} .
\end{aligned}
$$

Hence, we have

$$
\begin{aligned}
\left\|S_{\delta} x-S_{\delta} y\right\|^{2} \leq & \|x-y\|^{2}+\frac{2}{\delta}\left\langle x-S_{\delta} x, y-S_{\delta} y\right\rangle \\
& -(1-\delta)\left\|\left(x-S_{\delta} x\right)-\left(y-S_{\delta} y\right)\right\|^{2} .
\end{aligned}
$$


In particular, choosing in (19) $y=p$, where $p \in \operatorname{Fix}(S)=$ $\operatorname{Fix}\left(S_{\delta}\right)$ we obtain

$$
\left\|S_{\delta} x-p\right\|^{2} \leq\|x-p\|^{2}-(1-\delta)\left\|x-S_{\delta} x\right\|^{2} .
$$
result.

The following lemma is useful in the proof of our main

Lemma 10. Let $C$ be a nonempty closed and convex subspace of $H, u \in C$ fixed, $T$ a nonexpansive mapping from $C$ into itself, and $S$ a nonspreading mapping from $C$ into itself such that $\operatorname{Fix}(T) \cap \operatorname{Fix}(S) \neq \emptyset$. Consider a bounded sequence $\left(y_{n}\right)_{n \in \mathbb{N}} \subset C$. Then,

(1) if $\left\|y_{n}-T y_{n}\right\| \rightarrow 0$, as $n \rightarrow \infty$, then

$$
\limsup _{n \rightarrow \infty}\left\langle u-\bar{p}, y_{n}-\bar{p}\right\rangle \leq 0,
$$

where $\bar{p}=P_{\mathrm{Fix}(T)} u$ is the unique point in $\operatorname{Fix}(T)$ that satisfies the variational inequality

$$
\langle u-\bar{p}, x-\bar{p}\rangle \leq 0, \quad \forall x \in \operatorname{Fix}(T) .
$$

(2) If $\left\|y_{n}-S y_{n}\right\| \rightarrow 0$, as $n \rightarrow \infty$, then

$$
\limsup _{n \rightarrow \infty}\left\langle u-\widehat{p}, y_{n}-\widehat{p}\right\rangle \leq 0,
$$

where $\widehat{p}=P_{\mathrm{Fix}(S)} u$ is the unique point in $\operatorname{Fix}(S)$ that satisfies the variational inequality

$$
\langle u-\widehat{p}, x-\widehat{p}\rangle \leq 0, \quad \forall x \in \operatorname{Fix}(S) .
$$

(3) If $\left\|y_{n}-S y_{n}\right\| \rightarrow 0$ and $\left\|y_{n}-T y_{n}\right\| \rightarrow 0$, as $n \rightarrow \infty$, then

$$
\limsup _{n \rightarrow \infty}\left\langle u-p_{0}, y_{n}-p_{0}\right\rangle \leq 0
$$

where $p_{0}=P_{\operatorname{Fix}(T) \cap \operatorname{Fix}(S)} u$ is the unique point in $\operatorname{Fix}(T) \cap \operatorname{Fix}(S)$ that satisfies the variational inequality

$$
\left\langle u-p_{0}, x-p_{0}\right\rangle \leq 0, \quad \forall x \in \operatorname{Fix}(T) \cap \operatorname{Fix}(S) .
$$

Proof. (1) Let $\bar{p}$ satisfy (22). Let $\left(y_{n_{k}}\right)_{k \in \mathbb{N}}$ be a subsequence of $\left(y_{n}\right)_{n \in \mathbb{N}}$ for which

$$
\limsup _{n \rightarrow \infty}\left\langle\bar{p}-u, y_{n}-\bar{p}\right\rangle=\lim _{k \rightarrow \infty}\left\langle\bar{p}-u, y_{n_{k}}-\bar{p}\right\rangle .
$$

Select a subsequence $\left(y_{n_{k_{j}}}\right)_{j \in \mathbb{N}}$ of $\left(y_{n_{k}}\right)_{k \in \mathbb{N}}$ such that $y_{n_{k_{j}}} \rightarrow v$ (this is possible by boundedness of $\left.\left(y_{n}\right)_{n \in \mathbb{N}}\right)$. By the hypothesis $\left\|y_{n}-T y_{n}\right\| \rightarrow 0$, as $n \rightarrow \infty$, and by demiclosedness of $I-T$ at 0 we have $v \in \operatorname{Fix}(T)$ and

$$
\begin{aligned}
\limsup _{n \rightarrow \infty}\left\langle\bar{p}-u, y_{n}-\bar{p}\right\rangle & =\lim _{j \rightarrow \infty}\left\langle\bar{p}-u, y_{n_{k_{j}}}-\bar{p}\right\rangle \\
& =\langle\bar{p}-u, v-\bar{p}\rangle,
\end{aligned}
$$

so the claim follows by (22).
(2) The proof is the same of (1) since also $S$ is demiclosed in 0 .

(3) Select a subsequence $\left(y_{n_{k}}\right)_{k \in \mathbb{N}}$ of $\left(y_{n}\right)_{n \in \mathbb{N}}$ such that

$$
\limsup _{n \rightarrow \infty}\left\langle p_{0}-u, y_{n}-p_{0}\right\rangle=\lim _{k \rightarrow \infty}\left\langle p_{0}-u, y_{n_{k}}-p_{0}\right\rangle,
$$

where $p_{0}$ satisfies (26). Now select a subsequence $\left(y_{n_{k_{j}}}\right)_{j \in \mathbb{N}}$ of $\left(y_{n_{k}}\right)_{k \in \mathbb{N}}$ such that $y_{n_{k_{j}}} \rightarrow w$. Then by demiclosedness of $I-T$ and $I-S$ at 0 and by the hypotheses $\left\|y_{n}-T y_{n}\right\| \rightarrow 0$ and $\left\|y_{n}-S y_{n}\right\| \rightarrow 0$, as $n \rightarrow \infty$, we obtain that $w=T w=S w$, that is, $w \in \operatorname{Fix}(T) \cap \operatorname{Fix}(S)$. So,

$$
\begin{aligned}
\limsup _{n \rightarrow \infty}\left\langle p_{0}-u, y_{n}-p_{0}\right\rangle & =\lim _{j \rightarrow \infty}\left\langle p_{0}-u, y_{n_{k_{j}}}-p_{0}\right\rangle \\
& =\left\langle p_{0}-u, w-p_{0}\right\rangle,
\end{aligned}
$$

so the claim follows by (26).

A pertinent tool for us is the well-known lemma of $\mathrm{Xu}$ [18].

Lemma 11. Let $\left(a_{n}\right)_{n \in \mathbb{N}}$ be a sequence of nonnegative real numbers satisfying the following relation:

$$
a_{n+1} \leq\left(1-\alpha_{n}\right) a_{n}+\alpha_{n} \sigma_{n}+\theta_{n}, \quad n \geq 0,
$$

where,

(i) $\left(\alpha_{n}\right)_{n \in \mathbb{N}} \subset[0,1], \sum_{n=1}^{\infty} \alpha_{n}=\infty$;

(ii) $\limsup _{n \rightarrow \infty} \sigma_{n} \leq 0$;

(iii) $\theta_{n} \geq 0, \sum_{n=1}^{\infty} \theta_{n}<\infty$.

Then,

$$
\lim _{n \rightarrow \infty} a_{n}=0
$$

Finally, a crucial tool for our results is the following lemma proved by Maingé.

Lemma 12 (see [11]). Let $\left(\gamma_{n}\right)_{n \in \mathbb{N}}$ be a sequence of real numbers such that there exists a subsequence $\left(\gamma_{n_{j}}\right)_{j \in \mathbb{N}}$ of $\left(\gamma_{n}\right)_{n \in \mathbb{N}}$ such that $\gamma_{n_{j}}<\gamma_{n_{j}+1}$, for all $j \in \mathbb{N}$. Consider the sequence of integers $(\tau(n))_{n \in \mathbb{N}}$ defined by

$$
\tau(n):=\max \left\{k \leq n: \gamma_{k}<\gamma_{k+1}\right\} .
$$

Then, $(\tau(n))_{n \in \mathbb{N}}$ is a nondecreasing sequence for all $n \geq n_{0}$, satisfying

(i) $\lim _{n \rightarrow \infty} \tau(n)=\infty$;

(ii) $\gamma_{\tau_{(n)}}<\gamma_{\tau(n)+1}, \forall n \geq n_{0}$;

(iii) $\gamma_{n}<\gamma_{\tau(n)+1}, \forall n \geq n_{0}$.

\section{Main Result}

In all sections we denote by $T: C \rightarrow C$ a nonexpansive mapping, $S: C \rightarrow C$ a nonspreading mapping, and $T_{\delta}, S_{\delta}$ : $C \rightarrow C$ the respectively averaged type mappings. Moreover, 
$\left(\beta_{n}\right)_{n \in \mathbb{N}} \subset[0,1]$ denotes a real sequence and $U_{n}: C \rightarrow C$ denotes the convex combination of $T_{\delta}$ and $S_{\delta}$, that is,

$$
U_{n}=\beta_{n} T_{\delta} x_{n}+\left(1-\beta_{n}\right) S_{\delta} x_{n}, \quad n \in \mathbb{N} .
$$

Further we assume that

(i) $\operatorname{Fix}(S) \cap \operatorname{Fix}(T) \neq \emptyset$;

(ii) $\left(\alpha_{n}\right)_{n \in \mathbb{N}} \subset(0,1)$ a real sequence such that $\lim _{n \rightarrow \infty} \alpha_{n}=0$ and $\sum_{n=1}^{\infty} \alpha_{n}=0 ;$

(iii) $O(1)$ is any bounded real sequence.

We start with the following lemma:

Lemma 13. Let $u \in C$ be an anchor and let $\left(x_{n}\right)_{n \in \mathbb{N}}$ be the sequence defined by

$$
x_{n+1}=\alpha_{n} u+\left(1-\alpha_{n}\right) U_{n} x_{n}
$$

where

$$
U_{n}=\beta_{n} T_{\delta}+\left(1-\beta_{n}\right) S_{\delta}
$$

Then

(1) $U_{n}$ is quasi-nonexpansive for all $n \in \mathbb{N}$;

(2) $\left(x_{n}\right)_{n \in \mathbb{N}},\left(S x_{n}\right)_{n \in \mathbb{N}},\left(T x_{n}\right)_{n \in \mathbb{N}},\left(S_{\delta} x_{n}\right)_{n \in \mathbb{N}},\left(T_{\delta} x_{n}\right)_{n \in \mathbb{N}}$, $\left(U_{n} x_{n}\right)_{n \in \mathbb{N}}$ are bounded sequences.

Proof. (1) Any convex combination of quasi-nonexpansive mappings is quasi-nonexpansive too. So is every $U_{n}$, since $T_{\delta}$ and $S_{\delta}$ are quasi-nonexpansive.

(2) The boundedness of $\left(x_{n}\right)_{n \in \mathbb{N}}$ follows the fact that $U_{n}$ is quasi-nonexpansive. In fact, let $q \in \operatorname{Fix}(T) \cap \operatorname{Fix}(S)$. Then

$$
\begin{aligned}
& \left\|x_{n+1}-q\right\| \\
& \quad=\left\|\alpha_{n}(u-q)+\left(1-\alpha_{n}\right)\left(U_{n} x_{n}-q\right)\right\| \\
& \quad \leq \alpha_{n}\|u-q\|+\left(1-\alpha_{n}\right)\left\|U_{n} x_{n}-q\right\| \\
& \quad \leq \alpha_{n}\|u-q\|+\left(1-\alpha_{n}\right)\left\|x_{n}-q\right\| .
\end{aligned}
$$

Since

$$
\left\|x_{1}-q\right\| \leq \max \left\{\|u-q\|,\left\|x_{1}-q\right\|\right\},
$$

and by induction we assume that

$$
\left\|x_{n}-q\right\| \leq \max \left\{\|u-q\|,\left\|x_{1}-q\right\|\right\},
$$

and then

$$
\begin{aligned}
&\left\|x_{n+1}-q\right\| \\
& \leq \alpha_{n}\|u-q\| \\
&+\left(1-\alpha_{n}\right) \max \left\{\|u-q\|,\left\|x_{1}-q\right\|\right\} \\
& \leq \alpha_{n} \max \left\{\|u-q\|,\left\|x_{1}-q\right\|\right\} \\
&+\left(1-\alpha_{n}\right) \max \left\{\|u-q\|,\left\|x_{1}-q\right\|\right\} \\
&= \max \left\{\|u-q\|,\left\|x_{1}-q\right\|\right\} .
\end{aligned}
$$

Thus $\left(x_{n}\right)_{n \in \mathbb{N}}$ is bounded. The boundedness of the other sequences follows by boundedness of $\left(x_{n}\right)_{n \in \mathbb{N}}$ and by the quasi-nonexpansivity of involved mappings.

Now, we prove our strong convergence theorem.
Theorem 14. Let $H$ be a Hilbert space and let $C$ be a nonempty closed and convex subset of $H$. Let $T: C \rightarrow C$ be $a$ nonexpansive mapping and let $S: C \rightarrow C$ be a nonspreading mapping such that $\operatorname{Fix}(S) \cap \operatorname{Fix}(T) \neq \emptyset$. Let $T_{\delta}$ and $S_{\delta}$ be the averaged type mappings. Suppose that $\left(\alpha_{n}\right)_{n \in \mathbb{N}}$ is a real sequence in $(0,1)$ satisfying the conditions

(1) $\lim _{n \rightarrow \infty} \alpha_{n}=0$,

(2) $\sum_{n=1}^{\infty} \alpha_{n}=\infty$.

If $\left(\beta_{n}\right)_{n \in \mathbb{N}}$ is a sequence in $[0,1]$, we define a sequence $\left(x_{n}\right)_{n \in \mathbb{N}}$ as follows:

$$
\begin{gathered}
x_{1} \in C \\
x_{n+1}=\alpha_{n} u+\left(1-\alpha_{n}\right)\left[\beta_{n} T_{\delta} x_{n}+\left(1-\beta_{n}\right) S_{\delta} x_{n}\right], \quad n \in \mathbb{N} .
\end{gathered}
$$

Then, the following hold.

(i) If $\sum_{n=1}^{\infty}\left(1-\beta_{n}\right)<\infty$, then $\left(x_{n}\right)_{n \in \mathbb{N}}$ strongly converges to $\bar{p}=P_{\mathrm{Fix}(T)} u$ which is the unique solution in $\operatorname{Fix}(T)$ of the variational inequality $\langle u-\bar{p}, x-\bar{p}\rangle \leq 0$, for all $x \in \operatorname{Fix}(T)$.

(ii) If $\sum_{n=1}^{\infty} \beta_{n}<\infty$, then $\left(x_{n}\right)_{n \in \mathbb{N}}$ strongly converges to $\widehat{p}=P_{\mathrm{Fix}(S)}$ u which is the unique solution in $\operatorname{Fix}(S)$ of the variational inequality $\langle u-\widehat{p}, x-\widehat{p}\rangle \leq 0$, for all $x \in \operatorname{Fix}(S)$.

(iii) If $\lim \inf _{n \rightarrow \infty} \beta_{n}\left(1-\beta_{n}\right)>0$, then $\left(x_{n}\right)_{n \in \mathbb{N}}$ strongly converges to $p_{0}=P_{\operatorname{Fix}(T) \cap \operatorname{Fix}(S)} u$ which is the unique solution in $\operatorname{Fix}(T) \cap \operatorname{Fix}(S)$ of the variational inequality $\left\langle u-p_{0}, x-p_{0}\right\rangle \leq 0$, for all $x \in \operatorname{Fix}(T) \cap \operatorname{Fix}(S)$.

Proof. (i) We rewrite the sequence $\left(x_{n+1}\right)_{n \in \mathbb{N}}$ as

$$
x_{n+1}=\alpha_{n} u+\left(1-\alpha_{n}\right) T_{\delta} x_{n}+\left(1-\beta_{n}\right) E_{n}
$$

where $E_{n}=\left(1-\alpha_{n}\right)\left(S_{\delta} x_{n}-T_{\delta} x_{n}\right)$ is bounded, that is, $\left\|E_{n}\right\| \leq$ $O(1)$.

We begin to prove that $\lim _{n \rightarrow \infty}\left\|x_{n}-T_{\delta} x_{n}\right\|=0$.

Let $\bar{p} \in \operatorname{Fix}(T)=\operatorname{Fix}\left(T_{\delta}\right)$ the unique solution in $\operatorname{Fix}(T)$ of the variational inequality

$$
\langle u-\bar{p}, x-\bar{p}\rangle \leq 0, \quad \forall x \in \operatorname{Fix}(T) .
$$

We have

$$
\begin{aligned}
& \left\|x_{n+1}-\bar{p}\right\|^{2} \\
& =\| \alpha_{n} u+\left(1-\alpha_{n}\right)(1-\delta) x_{n} \\
& \quad+\left(1-\alpha_{n}\right) \delta T x_{n}+\left(1-\beta_{n}\right) E_{n}-\bar{p} \|^{2} \\
& =\|\left[\left(1-\alpha_{n}\right) \delta\left(T x_{n}-x_{n}\right)+x_{n}-\bar{p}\right] \\
& \quad+\left[\alpha_{n}\left(u-x_{n}\right)+\left(1-\beta_{n}\right) E_{n}\right] \|^{2}
\end{aligned}
$$


(by Lemma 4)

$$
\begin{aligned}
\leq & \left\|\left(1-\alpha_{n}\right) \delta\left(T x_{n}-x_{n}\right)+x_{n}-\bar{p}\right\|^{2} \\
& +2\left\langle\alpha_{n}\left(u-x_{n}\right)+\left(1-\beta_{n}\right) E_{n}, x_{n+1}-\bar{p}\right\rangle \\
\leq & \left\|\left(1-\alpha_{n}\right) \delta\left(T x_{n}-x_{n}\right)+x_{n}-\bar{p}\right\|^{2} \\
& +2 \alpha_{n}\left\langle u-x_{n}, x_{n+1}-\bar{p}\right\rangle+2\left(1-\beta_{n}\right)\left\langle E_{n}, x_{n+1}-\bar{p}\right\rangle \\
\leq & \left(1-\alpha_{n}\right)^{2} \delta^{2}\left\|T x_{n}-x_{n}\right\|^{2}+\left\|x_{n}-\bar{p}\right\|^{2} \\
& -2\left(1-\alpha_{n}\right) \delta\left\langle x_{n}-\bar{p}, x_{n}-T x_{n}\right\rangle \\
& +2 \alpha_{n}\left\|u-x_{n}\right\|\left\|x_{n+1}-\bar{p}\right\|+2\left(1-\beta_{n}\right)\left\|E_{n}\right\|\left\|x_{n+1}-\bar{p}\right\| \\
= & \left(1-\alpha_{n}\right)^{2} \delta^{2}\left\|x_{n}-T x_{n}\right\|^{2}+\left\|x_{n}-\bar{p}\right\|^{2} \\
((I- & T) \bar{p}=0) \\
& -2\left(1-\alpha_{n}\right) \delta\left\langle x_{n}-\bar{p},(I-T) x_{n}-(I-T) \bar{p}\right\rangle \\
& +\alpha_{n} O(1)+\left(1-\beta_{n}\right) O(1)
\end{aligned}
$$

(by Lemma 6)

$$
\begin{aligned}
\leq & \left\|x_{n}-\bar{p}\right\|^{2}+\left(1-\alpha_{n}\right)^{2} \delta^{2}\left\|x_{n}-T x_{n}\right\|^{2} \\
& -\left(1-\alpha_{n}\right) \delta\left\|(I-T) x_{n}-(I-T) \bar{p}\right\|^{2} \\
& +\alpha_{n} O(1)+\left(1-\beta_{n}\right) O(1) \\
= & \left\|x_{n}-\bar{p}\right\|^{2}-\left(1-\alpha_{n}\right) \delta\left[1-\delta\left(1-\alpha_{n}\right)\right]\left\|x_{n}-T x_{n}\right\|^{2} \\
& +\alpha_{n} O(1)+\left(1-\beta_{n}\right) O(1)
\end{aligned}
$$

and hence

$$
\begin{aligned}
0 \leq & \left(1-\alpha_{n}\right) \delta\left[1-\delta\left(1-\alpha_{n}\right)\right]\left\|x_{n}-T x_{n}\right\|^{2} \\
\leq & \left\|x_{n}-\bar{p}\right\|^{2}-\left\|x_{n+1}-\bar{p}\right\|^{2} \\
& +\alpha_{n} O(1)+\left(1-\beta_{n}\right) O(1) .
\end{aligned}
$$

We turn our attention to the monotony of the sequence $\left(\| x_{n}-\right.$ $\bar{p} \|)_{n \in \mathbb{N}}$.

We consider the following two cases.

Case A. $\left\|x_{n+1}-\bar{p}\right\|$ is definitively nonincreasing.

Case B. There exists a subsequence $\left(x_{n_{k}}\right)_{k \in \mathbb{N}}$ such that

$$
\left\|x_{n_{k}}-\bar{p}\right\|<\left\|x_{n_{k}+1}-\bar{p}\right\| \quad \forall k \in \mathbb{N} .
$$

Case A. Since $\left(\left\|x_{n}-\bar{p}\right\|\right)_{n \in \mathbb{N}}$ is definitively nonincreasing, $\lim _{n \rightarrow \infty}\left\|x_{n}-\bar{p}\right\|^{2}$ exists. From (45), $\lim _{n \rightarrow \infty} \alpha_{n}=0$, and $\sum_{n=1}^{\infty}\left(1-\beta_{n}\right)<\infty$, we have

$$
\begin{gathered}
0 \leq \limsup _{n \rightarrow \infty}\left(\left(1-\alpha_{n}\right) \delta\left[1-\delta\left(1-\alpha_{n}\right)\right]\left\|x_{n}-T x_{n}\right\|^{2}\right) \\
\leq \limsup _{n \rightarrow \infty}\left(\left\|x_{n}-\bar{p}\right\|^{2}-\left\|x_{n+1}-\bar{p}\right\|^{2}\right. \\
\left.\quad+\alpha_{n} O(1)+\left(1-\beta_{n}\right) O(1)\right)=0
\end{gathered}
$$

so, we can conclude that

$$
\begin{gathered}
\lim _{n \rightarrow \infty}\left\|x_{n}-T x_{n}\right\|=0, \\
\lim _{n \rightarrow \infty}\left\|x_{n}-T_{\delta} x_{n}\right\|=\lim _{n \rightarrow \infty} \delta\left\|x_{n}-T x_{n}\right\|=0 .
\end{gathered}
$$

By Lemma 10, it follows that

$$
\limsup _{n \rightarrow \infty}\left\langle u-\bar{p}, x_{n}-\bar{p}\right\rangle \leq 0 .
$$

Finally, we prove that $\left(x_{n}\right)_{n \in \mathbb{N}}$ converges strongly to $\bar{p}$. We compute that

$$
\begin{aligned}
& \left\|x_{n+1}-\bar{p}\right\|^{2} \\
& \quad=\left\|\alpha_{n}(u-\bar{p})+\left(1-\alpha_{n}\right)\left(T_{\delta} x_{n}-\bar{p}\right)+\left(1-\beta_{n}\right) E_{n}\right\|^{2}
\end{aligned}
$$

(by Lemma 4)

$$
\begin{aligned}
\leq & \left\|\alpha_{n}(u-\bar{p})+\left(1-\alpha_{n}\right)\left(T_{\delta} x_{n}-\bar{p}\right)\right\|^{2} \\
& +2\left(1-\beta_{n}\right)\left\langle E_{n}, x_{n+1}-\bar{p}\right\rangle \\
\leq & \alpha_{n}^{2}\|u-\bar{p}\|^{2}+\left(1-\alpha_{n}\right)^{2}\left\|T_{\delta} x_{n}-\bar{p}\right\|^{2} \\
& +2 \alpha_{n}\left(1-\alpha_{n}\right)\left\langle u-\bar{p}, T_{\delta} x_{n}-\bar{p}\right\rangle+\left(1-\beta_{n}\right) O(1)
\end{aligned}
$$

( $T_{\delta}$ nonexpansive)

$$
\begin{aligned}
\leq & \left(1-\alpha_{n}\right)\left\|x_{n}-\bar{p}\right\|^{2}+\alpha_{n}^{2} O(1) \\
& +2 \alpha_{n}\left(1-\alpha_{n}\right)\left\langle u-\bar{p}, T_{\delta} x_{n}-x_{n}\right\rangle \\
& +2 \alpha_{n}\left(1-\alpha_{n}\right)\left\langle u-\bar{p}, x_{n}-\bar{p}\right\rangle+\left(1-\beta_{n}\right) O(1) \\
\leq & \left(1-\alpha_{n}\right)\left\|x_{n}-\bar{p}\right\|^{2}+\alpha_{n}^{2} O(1)+\alpha_{n} O(1)\left\|T_{\delta} x_{n}-x_{n}\right\| \\
& +2 \alpha_{n}\left(1-\alpha_{n}\right)\left\langle u-\bar{p}, x_{n}-\bar{p}\right\rangle+\left(1-\beta_{n}\right) O(1) .
\end{aligned}
$$

If we put $\sigma_{n}=\alpha_{n} O(1)+O(1)\left\|T_{\delta} x_{n}-x_{n}\right\|+2\left(1-\alpha_{n}\right)\langle u-$ $\left.\bar{p}, x_{n}-\bar{p}\right\rangle$ and $\theta_{n}=\left(1-\beta_{n}\right) O(1)$, we have

$$
\left\|x_{n+1}-\bar{p}\right\|^{2} \leq\left(1-\alpha_{n}\right)\left\|x_{n}-\bar{p}\right\|^{2}+\alpha_{n} \sigma_{n}+\theta_{n} .
$$

Hence, from assumption $\sum_{n=1}^{\infty} \alpha_{n}=\infty$ and $\sum_{n=1}^{\infty}\left(1-\beta_{n}\right)<$ $\infty$, from (49) and lim $\sup _{n \rightarrow \infty}\left\langle u-\bar{p}, x_{n}-\bar{p}\right\rangle \leq 0$ we can apply Xu’s Lemma 11.

Case B. There exists a subsequence $\left(x_{n_{k}}\right)_{k \in \mathbb{N}}$ such that

$$
\left\|x_{n_{k}}-\bar{p}\right\|<\left\|x_{n_{k}+1}-\bar{p}\right\| \quad \forall k \in \mathbb{N} .
$$


Then by Maingé Lemma 12 there exists a sequence of integers $(\tau(n))_{n \in \mathbb{N}}$ that satisfies

(a) $(\tau(n))_{n \in \mathbb{N}}$ is nondecreasing;

(b) $\lim _{n \rightarrow \infty} \tau(n)=\infty$;

(c) $\left\|x_{\tau(n)}-\bar{p}\right\|<\left\|x_{\tau(n)+1}-\bar{p}\right\|$;

(d) $\left\|x_{n}-\bar{p}\right\|<\left\|x_{\tau(n)+1}-\bar{p}\right\|$.

Consequently,

$$
\begin{aligned}
0 & \leq \liminf _{n \rightarrow \infty}\left(\left\|x_{\tau(n)+1}-\bar{p}\right\|-\left\|x_{\tau(n)}-\bar{p}\right\|\right) \\
& \leq \limsup _{n \rightarrow \infty}\left(\left\|x_{\tau(n)+1}-\bar{p}\right\|-\left\|x_{\tau(n)}-\bar{p}\right\|\right) \\
& \leq \limsup _{n \rightarrow \infty}\left(\left\|x_{n+1}-\bar{p}\right\|-\left\|x_{n}-\bar{p}\right\|\right)
\end{aligned}
$$

(by (42))

$$
\begin{aligned}
=\limsup _{n \rightarrow \infty}( & \left\|\alpha_{n}\left(u-T_{\delta} x_{n}\right)+T_{\delta} x_{n}-\bar{p}+\left(1-\beta_{n}\right) E_{n}\right\| \\
- & \left.\left\|x_{n}-\bar{p}\right\|\right)
\end{aligned}
$$

( $T_{\delta}$ nonexpansive $)$

$$
\begin{aligned}
& \leq \limsup _{n \rightarrow \infty}\left(\alpha_{n} O(1)+\left\|x_{n}-\bar{p}\right\|+\left(1-\beta_{n}\right) O(1)-\left\|x_{n}-\bar{p}\right\|\right) \\
& =0
\end{aligned}
$$

so

$$
\lim _{n \rightarrow \infty}\left(\left\|x_{\tau(n)+1}-\bar{p}\right\|-\left\|x_{\tau(n)}-\bar{p}\right\|\right)=0
$$

By (45), we have

$$
\begin{aligned}
0 \leq & \left(1-\alpha_{\tau(n)}\right) \delta\left[1-\delta\left(1-\alpha_{\tau(n)}\right)\right]\left\|x_{\tau(n)}-T x_{\tau(n)}\right\|^{2} \\
\leq & \left\|x_{\tau(n)}-\bar{p}\right\|^{2}-\left\|x_{\tau(n)+1}-\bar{p}\right\|^{2} \\
& +\alpha_{n} O(1)+\left(1-\beta_{\tau(n)}\right) O(1),
\end{aligned}
$$

and from (55), $\lim _{n \rightarrow \infty} \alpha_{n}=0$ and $\sum_{n=1}^{\infty}\left(1-\beta_{n}\right)<\infty$ we get

$$
\lim _{n \rightarrow \infty}\left\|x_{\tau(n)}-T x_{\tau(n)}\right\|=0
$$

By Lemma 10 and (57) we have

$$
\limsup _{n \rightarrow \infty}\left\langle u-\bar{p}, x_{\tau(n)}-\bar{p}\right\rangle \leq 0
$$

Finally, we show that $\left(x_{n}\right)_{n \in \mathbb{N}}$ converges strongly to $\bar{p}$.

As in Case A, we can obtain

$$
\lim _{n \rightarrow \infty}\left\|x_{\tau(n)}-\bar{p}\right\|=0
$$

then, from property $(d)$ of Maingé Lemma 12 and (55) we can conclude

$$
\lim _{n \rightarrow \infty}\left\|x_{n}-\bar{p}\right\|=0
$$

Proof. (ii) Now, we rewrite the sequence $\left(x_{n+1}\right)_{n \in \mathbb{N}}$ as

$$
x_{n+1}=\alpha_{n} u+\left(1-\alpha_{n}\right) S_{\delta} x_{n}+\beta_{n} E_{n},
$$

where $E_{n}=\left(1-\alpha_{n}\right)\left(T_{\delta} x_{n}-S_{\delta} x_{n}\right)$ is bounded, that is, $\left\|E_{n}\right\| \leq$ $O(1)$.

We begin to prove that $\lim _{n \rightarrow \infty}\left\|x_{n}-S_{\delta} x_{n}\right\|=0$.

Let $\widehat{p} \in \operatorname{Fix}(S)=\operatorname{Fix}\left(S_{\delta}\right)$ the unique solution in $\operatorname{Fix}(S)$ of the variational inequality $\langle u-\widehat{p}, x-\widehat{p}\rangle \leq 0$, for all $x \in \operatorname{Fix}(S)$. We have

$$
\begin{aligned}
& \left\|x_{n+1}-\widehat{p}\right\|^{2} \\
& =\| \alpha_{n} u+\left(1-\alpha_{n}\right)(1-\delta) x_{n} \\
& \quad+\left(1-\alpha_{n}\right) \delta S x_{n}+\beta_{n} E_{n}-\widehat{p} \|^{2} \\
& =\|\left[\left(1-\alpha_{n}\right) \delta\left(S x_{n}-x_{n}\right)+x_{n}-\widehat{p}\right] \\
& \quad+\left[\alpha_{n}\left(u-x_{n}\right)+\beta_{n} E_{n}\right] \|^{2}
\end{aligned}
$$

(by Lemma 4)

$$
\begin{aligned}
\leq & \left\|\left(1-\alpha_{n}\right) \delta\left(S x_{n}-x_{n}\right)+x_{n}-\widehat{p}\right\|^{2} \\
& +2\left\langle\alpha_{n}\left(u-x_{n}\right)+\beta_{n} E_{n}, x_{n+1}-\widehat{p}\right\rangle \\
\leq & \left\|\left(1-\alpha_{n}\right) \delta\left(S x_{n}-x_{n}\right)+x_{n}-\widehat{p}\right\|^{2} \\
& +2 \alpha_{n}\left\langle u-x_{n}, x_{n+1}-\widehat{p}\right\rangle+2 \beta_{n}\left\langle E_{n}, x_{n}-\widehat{p}\right\rangle \\
\leq & \left(1-\alpha_{n}\right)^{2} \delta^{2}\left\|S x_{n}-x_{n}\right\|^{2}+\left\|x_{n}-\widehat{p}\right\|^{2} \\
& -2\left(1-\alpha_{n}\right) \delta\left\langle x_{n}-\widehat{p}, x_{n}-S x_{n}\right\rangle \\
& +\alpha_{n} O(1)+\beta_{n} O(1) \\
= & \left(1-\alpha_{n}\right)^{2} \delta^{2}\left\|x_{n}-S x_{n}\right\|^{2}+\left\|x_{n}-\widehat{p}\right\|^{2} \\
((I- & S) \hat{p}=0) \\
& -2\left(1-\alpha_{n}\right) \delta\left\langle x_{n}-\widehat{p},(I-S) x_{n}-(I-S) \widehat{p}\right\rangle \\
& +\alpha_{n} O(1)+\beta_{n} O(1)
\end{aligned}
$$

(by Lemma 8)

$$
\begin{aligned}
& \leq\left\|x_{n}-\hat{p}\right\|^{2}+\left(1-\alpha_{n}\right)^{2} \delta^{2}\left\|x_{n}-S x_{n}\right\|^{2} \\
& -2\left(1-\alpha_{n}\right) \delta\left[\left\|(I-S) x_{n}-(I-S) \hat{p}\right\|^{2}\right. \\
& \left.-\frac{1}{2}\left(\left\|x_{n}-S x_{n}\right\|^{2}+\|p-S p\|^{2}\right)\right] \\
& +\alpha_{n} O(1)+\beta_{n} O(1) \\
& \leq\left\|x_{n}-\widehat{p}\right\|^{2}+\left(1-\alpha_{n}\right)^{2} \delta^{2}\left\|x_{n}-S x_{n}\right\|^{2} \\
& -\left(1-\alpha_{n}\right) \delta\left\|x_{n}-S x_{n}\right\|^{2}+\alpha_{n} O(1)+\beta_{n} O(1)
\end{aligned}
$$




$$
\begin{aligned}
= & \left\|x_{n}-\widehat{p}\right\|^{2}-\left(1-\alpha_{n}\right) \delta\left[1-\delta\left(1-\alpha_{n}\right)\right]\left\|x_{n}-S x_{n}\right\|^{2} \\
& +\alpha_{n} O(1)+\beta_{n} O(1)
\end{aligned}
$$

and hence

$$
\begin{aligned}
0 \leq & \left(1-\alpha_{n}\right) \delta\left[1-\delta\left(1-\alpha_{n}\right)\right]\left\|x_{n}-S x_{n}\right\|^{2} \\
\leq & \left\|x_{n}-\widehat{p}\right\|^{2}-\left\|x_{n+1}-\widehat{p}\right\|^{2} \\
& +\alpha_{n} O(1)+\beta_{n} O(1) .
\end{aligned}
$$

Again, we turn our attention to the monotony of the sequence $\left(\left\|x_{n}-\widehat{p}\right\|\right)_{n \in \mathbb{N}}$. We consider the following two cases.

Case $A .\left\|x_{n+1}-\widehat{p}\right\|$ is definitively nonincreasing.

Case $B$. There exists a subsequence $\left(x_{n_{k}}\right)_{k \in \mathbb{N}}$ such that

$$
\left\|x_{n_{k}}-\hat{p}\right\|<\left\|x_{n_{k}+1}-\hat{p}\right\| \quad \forall k \in \mathbb{N}
$$

Case A. Since $\left(\left\|x_{n}-\widehat{p}\right\|\right)_{n \in \mathbb{N}}$ is definitively nonincreasing, $\lim _{n \rightarrow \infty}\left\|x_{n}-\widehat{p}\right\|^{2}$ exists. From (45), $\lim _{n \rightarrow \infty} \alpha_{n}=0$, and $\sum_{n=1}^{\infty} \beta_{n}<\infty$, we have

$$
\begin{gathered}
0 \leq \limsup _{n \rightarrow \infty}\left(\left(1-\alpha_{n}\right) \delta\left[1-\delta\left(1-\alpha_{n}\right)\right]\left\|x_{n}-S x_{n}\right\|^{2}\right) \\
\leq \limsup _{n \rightarrow \infty}\left(\left\|x_{n}-\widehat{p}\right\|^{2}-\left\|x_{n+1}-\widehat{p}\right\|^{2}\right. \\
\left.+\alpha_{n} O(1)+\beta_{n} O(1)\right)=0
\end{gathered}
$$

and hence

$$
\begin{gathered}
\lim _{n \rightarrow \infty}\left\|x_{n}-S x_{n}\right\|=0, \\
\lim _{n \rightarrow \infty}\left\|x_{n}-S_{\delta} x_{n}\right\|=\lim _{n \rightarrow \infty} \delta\left\|x_{n}-S x_{n}\right\|=0 .
\end{gathered}
$$

By Lemma 10, it follows that

$$
\limsup _{n \rightarrow \infty}\left\langle u-\widehat{p}, x_{n}-\widehat{p}\right\rangle \leq 0 \text {. }
$$

Finally, we prove that $\left(x_{n}\right)_{n \in \mathbb{N}}$ converges strongly to $\widehat{p}$.

$$
\text { We compute that }
$$

$$
\begin{aligned}
& \left\|x_{n+1}-\widehat{p}\right\|^{2} \\
& \quad=\left\|\alpha_{n}(u-\widehat{p})+\left(1-\alpha_{n}\right)\left(S_{\delta} x_{n}-\widehat{p}\right)+\beta_{n} E_{n}\right\|^{2}
\end{aligned}
$$

(by Lemma 4)

$$
\begin{aligned}
\leq & \left\|\alpha_{n}(u-\widehat{p})+\left(1-\alpha_{n}\right)\left(S_{\delta} x_{n}-\widehat{p}\right)\right\|^{2} \\
& +2 \beta_{n}\left\langle E_{n}, x_{n+1}-\widehat{p}\right\rangle \\
\leq & \alpha_{n}^{2}\|u-\widehat{p}\|^{2}+\left(1-\alpha_{n}\right)^{2}\left\|S_{\delta} x_{n}-\widehat{p}\right\|^{2} \\
& +2 \alpha_{n}\left(1-\alpha_{n}\right)\left\langle u-\widehat{p}, S_{\delta} x_{n}-\widehat{p}\right\rangle+\beta_{n} O(1)
\end{aligned}
$$

( $S_{\delta}$ quasi-nonexpansive)

$$
\begin{aligned}
\leq & \left(1-\alpha_{n}\right)\left\|x_{n}-\widehat{p}\right\|^{2}+\alpha_{n}^{2} O(1) \\
& +2 \alpha_{n}\left(1-\alpha_{n}\right)\left\langle u-\widehat{p}, S_{\delta} x_{n}-x_{n}\right\rangle \\
& +2 \alpha_{n}\left(1-\alpha_{n}\right)\left\langle u-\widehat{p}, x_{n}-\widehat{p}\right\rangle+\beta_{n} O(1) \\
\leq & \left(1-\alpha_{n}\right)\left\|x_{n}-\widehat{p}\right\|^{2}+\alpha_{n}^{2} O(1)+\alpha_{n} O(1)\left\|S_{\delta} x_{n}-x_{n}\right\| \\
& +2 \alpha_{n}\left(1-\alpha_{n}\right)\left\langle u-\widehat{p}, x_{n}-\widehat{p}\right\rangle+\beta_{n} O(1) .
\end{aligned}
$$

If we put $\sigma_{n}=\alpha_{n} O(1)+O(1)\left\|S_{\delta} x_{n}-x_{n}\right\|+2\left(1-\alpha_{n}\right)\langle u-$ $\left.\widehat{p}, x_{n}-\widehat{p}\right\rangle$ and $\theta_{n}=\beta_{n} O(1)$, we have

$$
\left\|x_{n+1}-\widehat{p}\right\|^{2} \leq\left(1-\alpha_{n}\right)\left\|x_{n}-\widehat{p}\right\|^{2}+\alpha_{n} \sigma_{n}+\theta_{n} .
$$

So, from assumption $\sum_{n=1}^{\infty} \alpha_{n}=\infty$ and $\sum_{n=1}^{\infty} \beta_{n}<\infty$, from (67) and lim $\sup _{n \rightarrow \infty}\left\langle\widehat{p}-u, x_{n}-\widehat{p}\right\rangle \geq 0$ we can apply Xu's Lemma 11.

Case $B$. There exists a subsequence $\left(x_{n_{k}}\right)_{k \in \mathbb{N}}$ such that

$$
\left\|x_{n_{k}}-\hat{p}\right\|<\left\|x_{n_{k}+1}-\hat{p}\right\| \quad \forall k \in \mathbb{N} .
$$

Then by Maingé Lemma there exists a sequence of integers $(\tau(n))_{n \in \mathbb{N}}$ that satisfies

(a) $(\tau(n))_{n \in \mathbb{N}}$ is nondecreasing;

(b) $\lim _{n \rightarrow \infty} \tau(n)=\infty$;

(c) $\left\|x_{\tau(n)}-\widehat{p}\right\|<\left\|x_{\tau(n)+1}-\widehat{p}\right\|$;

(d) $\left\|x_{n}-\widehat{p}\right\|<\left\|x_{\tau(n)+1}-\widehat{p}\right\|$.

Consequently,

$$
\begin{aligned}
0 & \leq \liminf _{n \rightarrow \infty}\left(\left\|x_{\tau(n)+1}-\hat{p}\right\|-\left\|x_{\tau(n)}-\hat{p}\right\|\right) \\
& \leq \limsup _{n \rightarrow \infty}\left(\left\|x_{\tau(n)+1}-\hat{p}\right\|-\left\|x_{\tau(n)}-\hat{p}\right\|\right) \\
& \leq \limsup _{n \rightarrow \infty}\left(\left\|x_{n+1}-\hat{p}\right\|-\left\|x_{n}-\widehat{p}\right\|\right)
\end{aligned}
$$

(by (61))

$$
=\limsup _{n \rightarrow \infty}\left(\left\|\alpha_{n}\left(u-S_{\delta} x_{n}\right)+S_{\delta} x_{n}-\hat{p}+\beta_{n} E_{n}\right\|-\left\|x_{n}-\hat{p}\right\|\right)
$$

$\left(S_{\delta}\right.$ quasi-nonexpansive $)$

$$
\leq \limsup _{n \rightarrow \infty}\left(\alpha_{n} O(1)+\left\|x_{n}-\hat{p}\right\|+\beta_{n} O(1)-\left\|x_{n}-\hat{p}\right\|\right)=0,
$$


so

$$
\lim _{n \rightarrow \infty}\left(\left\|x_{\tau(n)+1}-\widehat{p}\right\|-\left\|x_{\tau(n)}-\widehat{p}\right\|\right)=0
$$

By (63), we obtain

$$
\begin{aligned}
0 & \leq\left(1-\alpha_{\tau(n)}\right) \delta\left[1-\delta\left(1-\alpha_{\tau(n)}\right)\right]\left\|x_{\tau(n)}-S x_{\tau(n)}\right\|^{2} \\
& \leq\left\|x_{\tau(n)}-\hat{p}\right\|^{2}-\left\|x_{\tau(n)+1}-\hat{p}\right\|^{2}+\alpha_{n} O(1)+\beta_{\tau(n)} O(1),
\end{aligned}
$$

and from (73), $\lim _{n \rightarrow \infty} \alpha_{n}=0$ and $\sum_{n=1}^{\infty} \beta_{n}<\infty$ we get

$$
\lim _{n \rightarrow \infty}\left\|x_{\tau(n)}-S x_{\tau(n)}\right\|=0 .
$$

By Lemma 10 and (75) we get

$$
\limsup _{n \rightarrow \infty}\left\langle u-\widehat{p}, x_{\tau(n)-\widehat{p}}\right\rangle \leq 0 .
$$

Finally, we show that $\left(x_{n}\right)_{n \in \mathbb{N}}$ converges strongly to $\bar{p}$.

As in Case A, we obtain

$$
\lim _{n \rightarrow \infty}\left\|x_{\tau(n)}-\hat{p}\right\|=0,
$$

and then from property $(d)$ of Maingé Lemma and (73) we can conclude that

$$
\lim _{n \rightarrow \infty}\left\|x_{n}-\widehat{p}\right\|=0
$$

Proof. (iii) We recall that the sequence $\left(x_{n+1}\right)_{n \in \mathbb{N}}$ is defined as

$$
x_{n+1}=\alpha_{n} u+\left(1-\alpha_{n}\right) U_{n} x_{n}
$$

where $U_{n}=\beta_{n} T_{\delta} x_{n}+\left(1-\beta_{n}\right) S_{\delta} x_{n}$.

We first show that $\lim _{n \rightarrow \infty}\left\|x_{n}-U_{n} x_{n}\right\|=0$.

Let $p_{0} \in \operatorname{Fix}(T) \cap \operatorname{Fix}(S)$ be the unique solution of the variational inequality $\left\langle u-p_{0}, x-p_{0}\right\rangle \leq 0$, for all $x \in \operatorname{Fix}(T) \cap$ $\operatorname{Fix}(S)$. We compute that

$$
\begin{aligned}
& \left\|U_{n} x_{n}-p_{0}\right\|^{2} \\
& \quad=\left\|\beta_{n}\left(T_{\delta} x_{n}-p_{0}\right)+\left(1-\beta_{n}\right)\left(S_{\delta} x_{n}-p_{0}\right)\right\|^{2}
\end{aligned}
$$

(by Lemma 4)

$$
\begin{aligned}
= & \beta_{n}\left\|T_{\delta} x_{n}-p_{0}\right\|^{2}+\left(1-\beta_{n}\right)\left\|S_{\delta} x_{n}-p_{0}\right\|^{2} \\
& -\beta_{n}\left(1-\beta_{n}\right)\left\|T_{\delta} x_{n}-S_{\delta} x_{n}\right\|^{2}
\end{aligned}
$$

$\left(T_{\delta}\right.$ nonexpansive and by $\left.(20)\right)$

$$
\begin{aligned}
\leq & \beta_{n}\left\|x_{n}-p_{0}\right\|^{2}+\left(1-\beta_{n}\right)\left\|x_{n}-p_{0}\right\|^{2} \\
& -\left(1-\beta_{n}\right)(1-\delta)\left\|x_{n}-S_{\delta} x_{n}\right\|^{2} \\
& -\beta_{n}\left(1-\beta_{n}\right)\left\|T_{\delta} x_{n}-S_{\delta} x_{n}\right\|^{2} \\
= & \left\|x_{n}-p_{0}\right\|^{2}-\left(1-\beta_{n}\right)(1-\delta)\left\|x_{n}-S_{\delta} x_{n}\right\|^{2} \\
& -\beta_{n}\left(1-\beta_{n}\right)\left\|T_{\delta} x_{n}-S_{\delta} x_{n}\right\|^{2} .
\end{aligned}
$$

So, we get

$$
\begin{aligned}
\left\|U_{n} x_{n}-p_{0}\right\|^{2} \leq & \left\|x_{n}-p_{0}\right\|^{2} \\
& -\left(1-\beta_{n}\right)(1-\delta)\left\|x_{n}-S_{\delta} x_{n}\right\|^{2} \\
& -\beta_{n}\left(1-\beta_{n}\right)\left\|T_{\delta} x_{n}-S-\delta x_{n}\right\|^{2} .
\end{aligned}
$$

We have

$$
\begin{aligned}
& \left\|x_{n+1}-p_{0}\right\|^{2} \\
& =\left\|U_{n} x_{n}-p_{0}+\alpha_{n}\left(u-U_{n} x_{n}\right)\right\|^{2} \\
& \leq\left\|U_{n} x_{n}-p_{0}\right\|^{2} \\
& \quad+\alpha_{n}\left(\alpha_{n}\left\|u-U_{n} x_{n}\right\|^{2}\right. \\
& \left.\quad+2\left\|U_{n} x_{n}-p_{0}\right\|\left\|u-U_{n} x_{n}\right\|\right) \\
& \leq\left\|U_{n} x_{n}-p_{0}\right\|^{2}+\alpha_{n} O(1)
\end{aligned}
$$

(by $(81)$ )

$$
\begin{aligned}
\leq & \left\|x_{n}-p_{0}\right\|^{2}-\left(1-\beta_{n}\right)(1-\delta)\left\|x_{n}-S_{\delta} x_{n}\right\|^{2} \\
& -\beta_{n}\left(1-\beta_{n}\right)\left\|T_{\delta} x_{n}-S_{\delta} x_{n}\right\|^{2}+\alpha_{n} O(1) .
\end{aligned}
$$

From (82), we derive

$$
\begin{aligned}
& \left(1-\beta_{n}\right)(1-\delta)\left\|x_{n}-S_{\delta} x_{n}\right\|^{2} \\
& \quad \leq\left\|x_{n}-p_{0}\right\|^{2}-\left\|x_{n+1}-p_{0}\right\|^{2}+\alpha_{n} O(1), \\
& \beta_{n}\left(1-\beta_{n}\right)\left\|T_{\delta} x_{n}-S_{\delta} x_{n}\right\|^{2} \\
& \quad \leq\left\|x_{n}-p_{0}\right\|^{2}-\left\|x_{n+1}-p_{0}\right\|^{2}+\alpha_{n} O(1) .
\end{aligned}
$$

Now, also we consider two cases.

Case $A .\left\|x_{n+1}-\widehat{p_{0}}\right\|$ is definitively nonincreasing.

Case $B$. There exists a subsequence $\left(x_{n_{k}}\right)_{k \in \mathbb{N}}$ such that

$$
\left\|x_{n_{k}}-\widehat{p_{0}}\right\|<\left\|x_{n_{k}+1}-\widehat{p_{0}}\right\| \quad \forall k \in \mathbb{N} .
$$

Case $A$. Since $\left(\left\|x_{n}-p_{0}\right\|\right)_{n \in \mathbb{N}}$ is definitively nonincreasing, $\lim _{n \rightarrow \infty}\left\|x_{n}-p_{0}\right\|^{2}$ exists. From (83) and $\lim _{n \rightarrow \infty} \alpha_{n}=0$ and since lim inf $\operatorname{in}_{n \rightarrow \infty} \beta_{n}\left(1-\beta_{n}\right)>0$ we conclude that

$$
\lim _{n \rightarrow \infty}\left\|x_{n}-S_{\delta} x_{n}\right\|=\lim _{n \rightarrow \infty} \delta\left\|x_{n}-S x_{n}\right\|=0 .
$$

Furthermore, from (84) we have

$$
\lim _{n \rightarrow \infty}\left\|S_{\delta} x_{n}-T_{\delta} x_{n}\right\|=\lim _{n \rightarrow \infty} \delta\left\|S x_{n}-T x_{n}\right\|=0 ;
$$

since

$$
\left\|x_{n}-T x_{n}\right\| \leq\left\|x_{n}-S x_{n}\right\|+\left\|S x_{n}-T x_{n}\right\|,
$$

by (86) and (87) we obtain

$$
\lim _{n \rightarrow \infty}\left\|x_{n}-T_{\delta} x_{n}\right\|=\lim _{n \rightarrow \infty} \delta\left\|x_{n}-T x_{n}\right\|=0 .
$$


Then, since

$\left\|U_{n} x_{n}-x_{n}\right\| \leq \beta_{n}\left\|T_{\delta} x_{n}-x_{n}\right\|+\left(1-\beta_{n}\right)\left\|S_{\delta} x_{n}-x_{n}\right\|$,

by (86) and (89) we get

$$
\lim _{n \rightarrow \infty}\left\|x_{n}-U_{n} x_{n}\right\|=0
$$

By Lemma 10, we have

$$
\limsup _{n \rightarrow \infty}\left\langle u-p_{0}, x_{n}-p_{0}\right\rangle \leq 0
$$

Finally, $\left(x_{n}\right)_{n \in \mathbb{N}}$ converges strongly to $p_{0}$.

We compute that

$$
\begin{aligned}
&\left\|x_{n+1}-p_{0}\right\|^{2} \\
& \leq\left\|\left(1-\alpha_{n}\right)\left(U_{n} x_{n}-p_{0}\right)+\alpha_{n}\left(u-p_{0}\right)\right\| \\
&=\left(1-\alpha_{n}\right)^{2}\left\|U_{n} x_{n}-p_{0}\right\|^{2}+\alpha_{n}^{2}\left\|u-p_{0}\right\|^{2} \\
&+2 \alpha_{n}\left(1-\alpha_{n}\right)\left\langle U_{n} x_{n}-p_{0}, u-p_{0}\right\rangle
\end{aligned}
$$

( $U_{n}$ quasi-nonexpansive)

$$
\begin{aligned}
\leq & \left(1-\alpha_{n}\right)^{2}\left\|x_{n}-p_{0}\right\|^{2}+\alpha_{n}^{2} O(1) \\
& +2 \alpha_{n}\left(1-\alpha_{n}\right)\left\langle U_{n} x_{n}-x_{n}, u-p_{0}\right\rangle \\
& +2 \alpha_{n}\left(1-\alpha_{n}\right)\left\langle x_{n}-p_{0}, u-p_{0}\right\rangle \\
\leq & \left(1-\alpha_{n}\right)\left\|x_{n}-p_{0}\right\|^{2}+\alpha_{n}^{2} O(1)+\alpha_{n} O(1)\left\|U_{n} x_{n}-x_{n}\right\| \\
& +2 \alpha_{n}\left(1-\alpha_{n}\right)\left\langle x_{n}-p_{0}, u-p_{0}\right\rangle .
\end{aligned}
$$

If we set $\sigma_{n}=\alpha_{n} O(1)+O(1)\left\|U_{n} x_{n}-x_{n}\right\|+2\left(1-\alpha_{n}\right)\left\langle x_{n}-\right.$ $\left.p_{0}, u-p_{0}\right\rangle$, we have

$$
\left\|x_{n+1}-p_{0}\right\|^{2} \leq\left(1-\alpha_{n}\right)\left\|x_{n}-p_{0}\right\|^{2}+\alpha_{n} \sigma_{n} .
$$

From $\sum_{n=1}^{\infty} \alpha_{n}=\infty,(91)$, and $\lim \sup _{n \rightarrow \infty}\left\langle u-p_{0}, x_{n}-p_{0}\right\rangle \leq$ 0 we conclude that $\left(x_{n}\right)_{n \in \mathbb{N}}$ strongly converges to $p_{0}$.

Case B. $\left(\left\|x_{n}-p_{0}\right\|\right)_{n \in \mathbb{N}}$ is not definitively nonincreasing. This means that there exists a subsequence $\left(x_{n_{k}}\right)_{k \in \mathbb{N}}$ such that

$$
\left\|x_{n_{k}}-p_{0}\right\|<\left\|x_{n_{k}+1}-p_{0}\right\| \quad \forall k \in \mathbb{N} .
$$

Then by Maingé Lemma 12 there exists a sequence of integers $(\tau(n))_{n \in \mathbb{N}}$ that satisfies some properties defined previously.
Consequently,

$$
\begin{aligned}
0 & \leq \liminf _{n \rightarrow \infty}\left(\left\|x_{\tau(n)+1}-p_{0}\right\|-\left\|x_{\tau(n)}-p_{0}\right\|\right) \\
& \leq \limsup _{n \rightarrow \infty}\left(\left\|x_{\tau(n)+1}-p_{0}\right\|-\left\|x_{\tau(n)}-p_{0}\right\|\right) \\
& \leq \limsup _{n \rightarrow \infty}\left(\left\|x_{n+1}-p_{0}\right\|-\left\|x_{n}-p_{0}\right\|\right)
\end{aligned}
$$

(by (79))

$$
=\limsup _{n \rightarrow \infty}\left(\left\|\alpha_{n}\left(u-p_{0}\right)+\left(1-\alpha_{n}\right)\left(U_{n} x_{n}-p_{0}\right)\right\|\right.
$$

$$
\left.-\left\|x_{n}-p_{0}\right\|\right)
$$

( $U_{n}$ quasi-nonexpansive)

$$
\leq \limsup _{n \rightarrow \infty}\left(\alpha_{n} O(1)+\left\|x_{n}-p_{0}\right\|-\left\|x_{n}-p_{0}\right\|\right)=0,
$$

and hence

$$
\lim _{n \rightarrow \infty}\left(\left\|x_{\tau(n)+1}-p_{0}\right\|-\left\|x_{\tau(n)}-p_{0}\right\|\right)=0 .
$$

By (83) we get

$$
\begin{aligned}
& \left(1-\beta_{\tau(n)}\right)(1-\delta)\left\|x_{\tau(n)}-S_{\delta} x_{\tau(n)}\right\|^{2} \\
& \quad \leq\left\|x_{\tau(n)}-p_{0}\right\|^{2}-\left\|x_{n+1}-p_{0}\right\|^{2}+\alpha_{\tau(n)} O(1),
\end{aligned}
$$

and by(84) we have

$$
\begin{aligned}
& \beta_{\tau(n)}\left(1-\beta_{\tau(n)}\right)\left\|T_{\delta} x_{\tau(n)}-S_{\delta} x_{\tau(n)}\right\|^{2} \\
& \quad \leq\left\|x_{\tau(n)}-p_{0}\right\|^{2}-\left\|x_{n+1}-p_{0}\right\|^{2}+\alpha_{\tau(n)} O(1) .
\end{aligned}
$$

As in Case A, we get
(a) $\lim _{n \rightarrow \infty}\left\|x_{\tau(n)}-S x_{\tau(n)}\right\|=0$,
(b) $\lim _{n \rightarrow \infty}\left\|x_{\tau(n)}-T x_{\tau(n)}\right\|=0$,
(c) $\lim _{n \rightarrow \infty}\left\|x_{\tau(n)}-U_{\tau(n)} x_{\tau(n)}\right\|=0$.

By Lemma 10, (a) and (b) we have

$$
\limsup _{n \rightarrow \infty}\left\langle u-p_{0}, x_{\tau(n)}-p_{0}\right\rangle \leq 0 .
$$

Finally, we prove that $\left(x_{n}\right)_{n \in \mathbb{N}}$ converges strongly to $p_{0}$.

As in Case A, using (c), the assumption $\sum_{n=1}^{\infty} \alpha_{n}=\infty$, and (100) we can apply Xu's Lemma 11 and conclude that

$$
\lim _{n \rightarrow \infty}\left\|x_{\tau(n)}-\hat{p}\right\|=0,
$$

and then from property $(d)$ of Maingé Lemma and (97) we can derive that

$$
\lim _{n \rightarrow \infty}\left\|x_{n}-p_{0}\right\|=0
$$

Remark 15. We remark that in order to prove that

$$
\begin{gathered}
\left\|x_{n}-T x_{n}\right\| \longrightarrow 0, \quad\left\|x_{n}-S x_{n}\right\| \longrightarrow 0, \\
\left\|x_{n}-U_{n} x_{n}\right\| \longrightarrow 0,
\end{gathered}
$$

we do not follow the line of the proof of Song and Chai in [4] because their techniques seem questionable. 
Remark 16. The main result of this paper gives a positive answer to the question of Kurokawa and Takahashi; see Remark page 1567 in [19].

\section{Conflict of Interests}

The authors declare that they have no competing interests.

\section{References}

[1] B. Halpern, "Fixed points of nonexpanding maps," Bulletin of the American Mathematical Society, vol. 73, pp. 957-961, 1967.

[2] C. E. Chidume and C. O. Chidume, "Iterative approximation of fixed points of nonexpansive mappings," Journal of Mathematical Analysis and Applications, vol. 318, no. 1, pp. 288-295, 2006.

[3] T. Suzuki, "A sufficient and necessary condition for Halperntype strong convergence to fixed points of nonexpansive mappings," Proceedings of the American Mathematical Society, vol. 135, no. 1, pp. 99-106, 2007.

[4] Y. Song and X. Chai, "Halpern iteration for firmly type nonexpansive mappings," Nonlinear Analysis: Theory, Methods \& Applications, vol. 71, no. 10, pp. 4500-4506, 2009.

[5] S. Saejung, "Halpern's iteration in Banach spaces," Nonlinear Analysis: Theory, Methods and Applications, vol. 73, no. 10, pp. 3431-3439, 2010.

[6] F. Kohsaka and W. Takahashi, "Fixed point theorems for a class of nonlinear mappings related to maximal monotone operators in Banach spaces," Archiv der Mathematik, vol. 91, no. 2, pp. 166$177,2008$.

[7] S. Iemoto and W. Takahashi, "Approximating common fixed points of nonexpansive mappings and nonspreading mappings in a Hilbert space," Nonlinear Analysis: Theory, Methods \& Applications, vol. 71, no. 12, pp. e2082-e2089, 2009.

[8] S. Itoh and W. Takahashi, "The common fixed point theory of singlevalued mappings and multivalued mappings," Pacific Journal of Mathematics, vol. 79, no. 2, pp. 493-508, 1978.

[9] M. O. Osilike and F. O. Isiogugu, "Weak and strong convergence theorems for nonspreading-type mappings in Hilbert spaces," Nonlinear Analysis: Theory, Methods and Applications, vol. 74, no. 5, pp. 1814-1822, 2011.

[10] A. Moudafi, "Krasnoselski-Mann iteration for hierarchical fixed-point problems," Inverse Problems, vol. 23, no. 4, pp. 16351640, 2007.

[11] P. Maingé, "Strong convergence of projected subgradient methods for nonsmooth and nonstrictly convex minimization," SetValued Analysis, vol. 16, no. 7-8, pp. 899-912, 2008.

[12] P. E. Maingé, "The viscosity approximation process for quasinonexpansive mappings in Hilbert spaces," Computers \& Mathematics with Applications, vol. 59, no. 1, pp. 74-79, 2010.

[13] K. Wongchan and S. Saejung, "On the strong convergence of viscosity approximation process for quasinonexpansive mappings in Hilbert spaces," Abstract and Applied Analysis, vol. 2011, Article ID 385843, 9 pages, 2011.

[14] W. Takahashi, Nonlinear Functional Analysis, Yokohama Publishers, Yokohama, Japan, 2000.

[15] C. Byrne, "A unified treatment of some iterative algorithms in signal processing and image reconstruction," Inverse Problems, vol. 20, no. 1, pp. 103-120, 2004.

[16] F. E. Browder and W. V. Petryshyn, "Semicontractive and semiaccretive nonlinear mappings in Banach spaces," Bulletin of the American Mathematical Society, vol. 74, pp. 660-665, 1968.
[17] A. Moudafi, "Split monotone variational inclusions," Journal of Optimization Theory and Applications, vol. 150, no. 2, pp. 275283, 2011.

[18] H. K. Xu, "Iterative algorithms for nonlinear operators," Journal of the London Mathematical Society, vol. 66, no. 1, pp. 240-256, 2002.

[19] Y. Kurokawa and W. Takahashi, "Weak and strong convergence theorems for nonspreading mappings in Hilbert spaces," Nonlinear Analysis: Theory, Methods \& Applications, vol. 73, no. 6, pp. 1562-1568, 2010. 


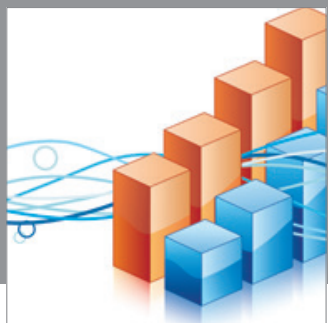

Advances in

Operations Research

mansans

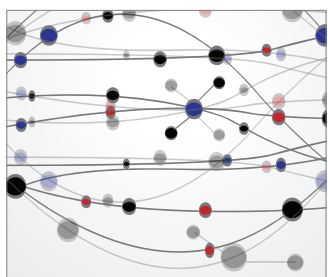

The Scientific World Journal
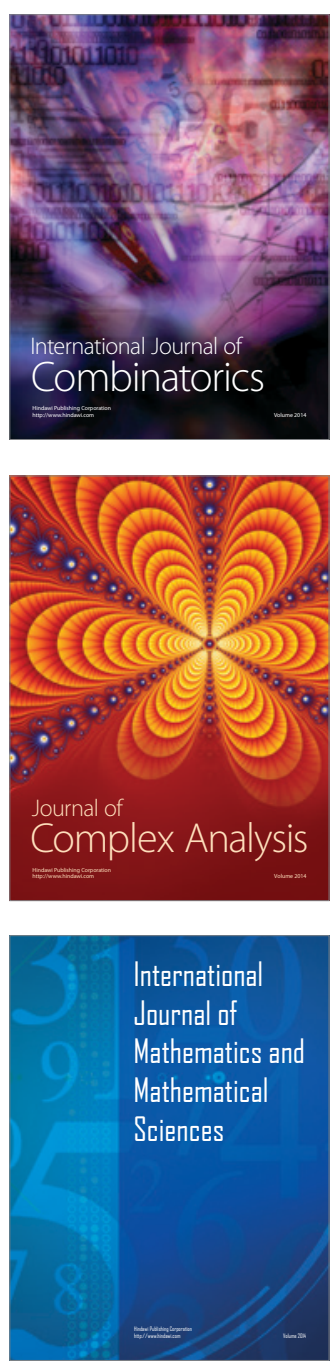
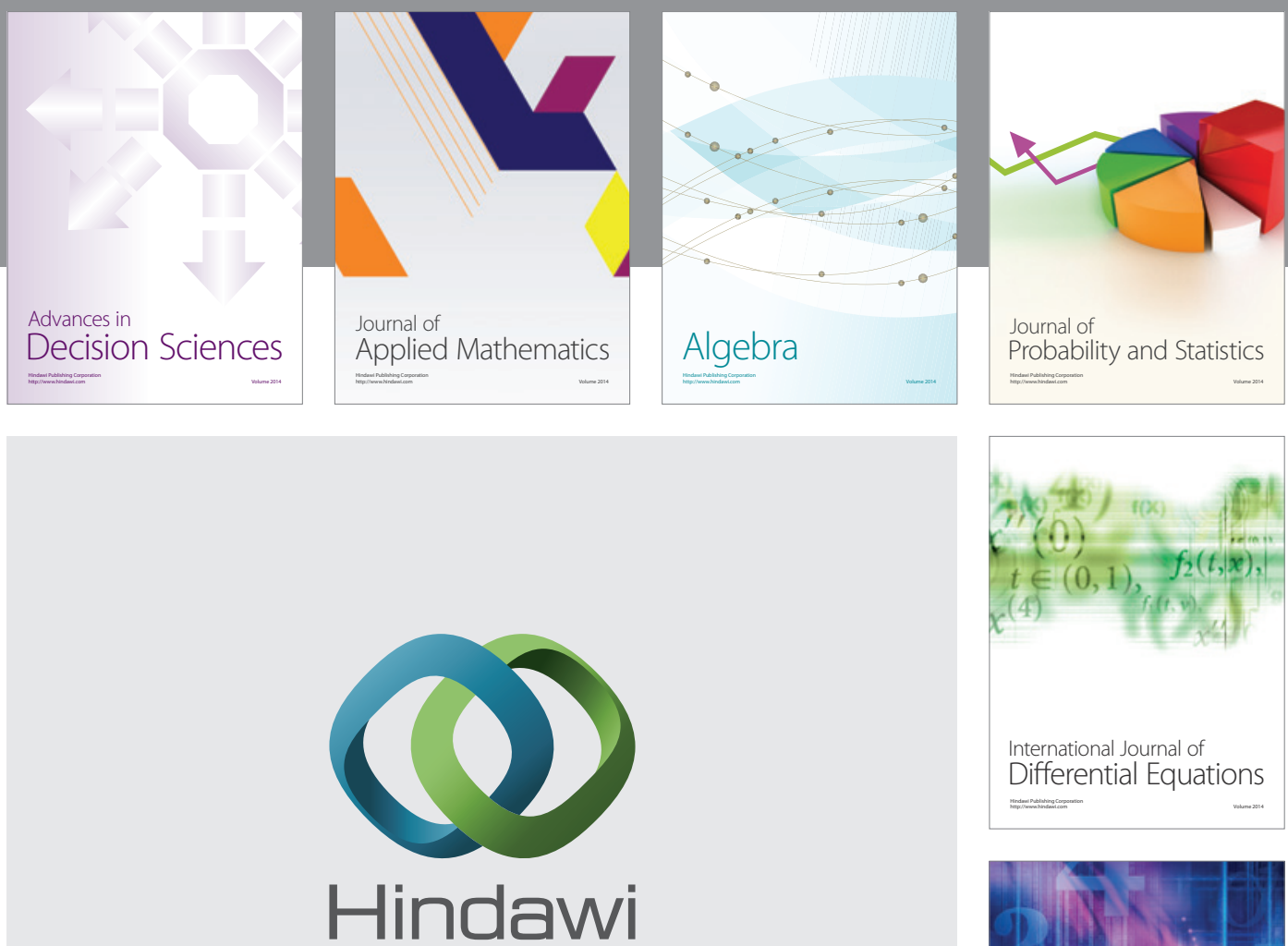

Submit your manuscripts at http://www.hindawi.com
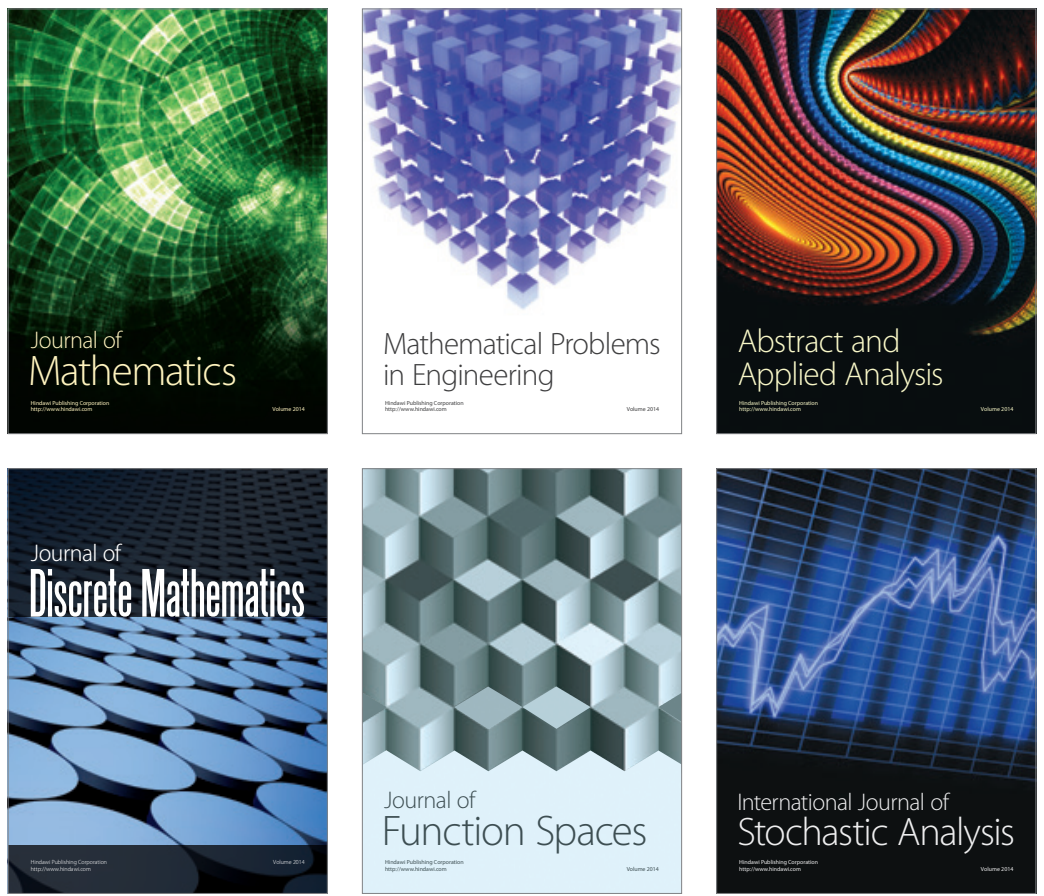

Journal of

Function Spaces

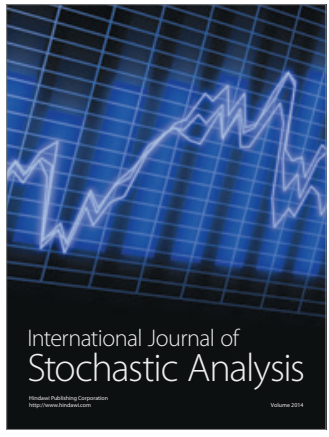

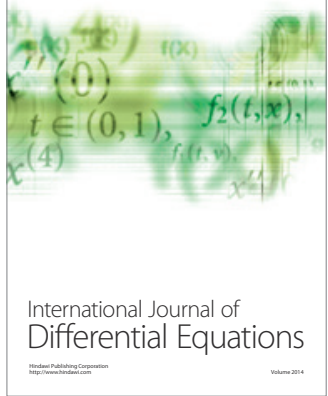
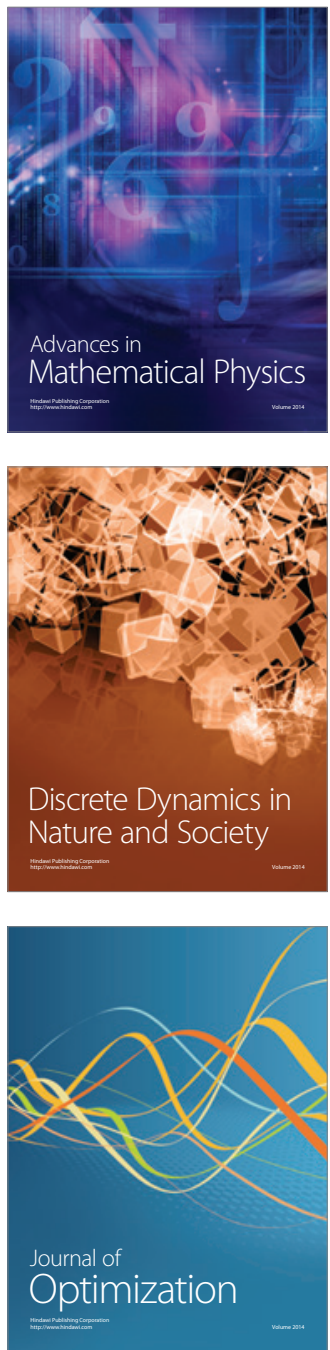